\title{
O noir e a mise-en-scène em Vivian Maier: imaginário em torno da babá-fotógrafa ${ }^{1}$ The noir and the mise-en-scène in Vivian Maier: the imaginary around the nanny
}

\author{
Fabíola Paes de Almeida Tarapanoff \\ Professora do curso de Comunicação Social da FIAM-FAAM-Centro Universitário, Brasil. Doutora em Comunicação pela \\ Universidade Metodista de São Paulo, Brasil. E-mail: fatarapanoff@gmail.com
}

\section{Márcia Rodrigues da Costa}

Professora do curso de Jornalismo da Unesp-Bauru, Brasil. Doutora em Comunicação Social pela Universidade Metodista de São Paulo e Pós-doutorada em Comunicação e Cultura pela Universidade de Sorocaba, Brasil, com bolsa CAPES. E-mail: marciarcosta13@gmail.com

\section{Resumo:}

O artigo estabelece relações entre a obra de Vivian Maier e a estética noir, também presente na obra de Alfred Hitchcock, partindo da concepção do imaginário como propulsor da imagem. A atuação da fotógrafa, revelada depois de décadas ocultada pela profissão de babá, é analisada conforme os elementos dos filmes noir, como o suspense, o mistério, a fantasia, os contrastes entre o claro e o escuro, a expressividade e a narrativa em primeira pessoa, presentes em sua mise-en-scène. Conclui-se que suas imagens atraíram tamanho interesse no mundo principalmente pela forma que a fotógrafa constrói suas imagens ficcionais, permeadas pelo imaginário do noir.

\section{Palavras-chave:}

Fotografia; Mise-en-scène; Vivian Maier; Autorretrato; Cinema noir.

\begin{abstract}
:
The article establishes relationships between the work of Vivian Maier and the aesthetic noir, also present in the work of Alfred Hitchcock, starting from the conception of the imaginary as propeller of the image. The work of the photographer, revealed after being concealed by the profession of nanny for decades, is analyzed according to the elements of the noir movies, as the thriller, the mystery, the fantasy, the contrasts between the clear and the dark, the expressivity and the first person narrative, present on his mise-en-scène. It is concluded that her images have attracted much interest in the world mainly because of the way the photographer constructs her fictional images, permeated by the imagery of the noir.
\end{abstract}

\section{Keywords:}

Photography; Mise-en-scène; Vivian Maier; Self-portrait; Noir movies.

\section{Introdução}

\footnotetext{
${ }^{1}$ Uma versão preliminar do presente artigo foi apresentada no "XXXIX Congresso Brasileiro de Ciências da Comunicação" - São Paulo - SP, 2016.
}

INTERIN, v. 23, n. 2, jul./dez. 2018. ISSN: 1980-5276. 
Este artigo analisa autorretratos de Vivian Maier, conhecida como a babáfotógrafa que atuou por várias décadas nos Estados Unidos (EUA), até sua morte, nos anos 1990. Nosso foco são as imagens produzidas por ela na década de 1950, em que observamos sua mise-en-scène, a forma como ela constrói a cena utilizando elementos do cinema noir.

Assim, em seus autorretratos, ela registra sua própria imagem com sua câmera, ao mesmo tempo em que, por trás dessa câmera, dirige sua ação. Como Alfred Hitchcock, Vivian Maier, ao se projetar na própria cena que construía, fazia uso do imaginário como propulsor da imagem, despertando o interesse do público por sua vida-obra.

Ao longo do artigo apresentamos a fotógrafa, discutimos o conceito de miseen-scène, abordamos o cinema noir e debatemos a questão do imaginário na criação da imagem, utilizando principalmente o pensamento de autores como Jacques Aumont, Michel Maffesoli e Philippe Dubois. Em seguida, observamos a mise-enscène de Vivian Maier conforme o enquadramento, o gesto, a iluminação e a maneira como ela se movimenta, se colocando no espaço, na cena.

Nas fotografias de Vivian Maier enxergamos a presença dos elementos dos filmes noir, como o suspense, o mistério, a fantasia, os contrastes entre o claro e o escuro, a expressividade e a narrativa em primeira pessoa, presentes em sua mise-enscène. Ao final, concluímos que a forma como a fotógrafa constrói suas imagens ficcionais vai além do real. Permeados pelo clima do noir, seus autorretratos são grandes propulsores do imaginário.

\section{Sobre Vivian Maier}

Após 50 anos mantendo segredo sobre o seu ofício, a obra de Vivian Maier ganhou notoriedade depois que o historiador John Maloof comprou os negativos de suas fotos em uma casa de leilão em 2007, na cidade de Chicago (EUA) e os divulgou mundialmente por meio da mídia, organizando exposições, livros e um documentário. Foi, portanto, somente depois da morte da fotógrafa que o mundo passou a conhecer sua história e sua produção.

INTERIN, v. 23, n. 2, jul./dez. 2018. ISSN: 1980-5276. 
A figura da talentosa fotógrafa foi, por ela mesma, ocultada pela figura da babá. No entanto, Vivian Maier, que aparentemente nunca estudou formalmente a fotografia, produziu mais de 100 mil imagens entre 1950 e 1990 coletadas em dezenas de países, principalmente nos EUA. Maloof deparou-se com inúmeros registros que ela produziu em diversas cidades, essencialmente em Chicago e New York, durante os quarenta anos em que a fotógrafa viveu nos Estados Unidos. Parte da sua produção realizada de forma catártica, espontânea e sensível consta no livro organizado pelo historiador, intitulado Vivian Maier: uma fotógrafa de rua (2014), o único traduzido no Brasil.

A câmera de Vivian Maier registrava cada momento que lhe atraísse a atenção, como moradores de rua, afrodescendentes, animais, o comércio ativo, as mulheres, em muitas cenas que captavam o espírito da cidade em transformação (como ruínas de casas antigas e construções novas). Produziu muitos autorretratos, tema do qual nos ocupamos neste artigo.

Muito da visão sobre o trabalho de Vivian Maier parte de um imaginário em torno de sua figura, difundido no filme Finding Vivian Maier (MALOOF; SISKEL, 2013), focado no mistério da babá fotógrafa, e no livro organizado por ele. Aqueles que conviveram com a babá contam no documentário que ela era uma pessoa de hábitos excêntricos (como colecionar jornais com notícias bizarras e muitos outros tipos de objetos, agrupados por ela em um grande galpão alugado), uma pessoa de vida reservada e misteriosa. Vivian Maier viveu de maneira extremamente privada, provavelmente nunca se casou, não teve filhos, nem nutriu muitas amizades, contam os entrevistados. Eis "[...] alguém que existe unicamente nas coisas que viu”, escreveu Geoff Dyer no livro organizado por Maloof (2014, p. 8). Dyer afirma que ela, como babá ou governanta, "figura clássica da ficção vitoriana", era "uma estranha cujo acesso à vida doméstica permite o desenvolvimento, como nenhum outro, do dom da observação" (2014, p. 9). O autor finaliza a apresentação da obra citando Vivian Maier como uma mulher "solitária, de aparência excêntrica, embrulhada em sobretudos, abrigando o segredo de uma vida inteira, intuído pela dádiva do escrutínio momentâneo da câmera" (DYER, 2014, p. 9). O discurso da estranheza, do mistério, da não adequação de Maier aos padrões impostos às mulheres de sua época (a

INTERIN, v. 23, n. 2, jul./dez. 2018. ISSN: 1980-5276.

Fabíola Paes de Almeida Tarapanoff; Márcia Rodrigues da Costa. O noir e a mise-en-scène em Vivian Maier: o imaginário em torno da babá-fotógrafa. p. 4-21. 
maternidade, o casamento) está bastante presente tanto no livro quanto no filme, ambos organizados por Maloof.

Partimos, portanto, destas informações sobre como sua biografia foi difundida por Maloof e avançamos buscando investigar uma possível influência da estética noir nos autorretratos e na mise-en-scène de Maier, o que, acreditamos, pode ter ajudado a alimentar um determinado imaginário sobre ela. Interessam-nos aqui alguns autorretratos de Maier produzidos nos anos 1950, utilizando a cidade e espaços privados como cenário para sua mise-en-scène. Tal qual um personagem do cinema de Alfred Hitchcock, sua figura surge de forma curiosa e surpreendente na cena, como ocorre, por exemplo, na figura 1, em que projeta sua imagem em um espelho que está sendo movimentado na rua por um trabalhador, surgindo inusitadamente no cenário e surpreendendo o olhar do espectador.

Fig. 1 - Autorretrato de Vivian Maier

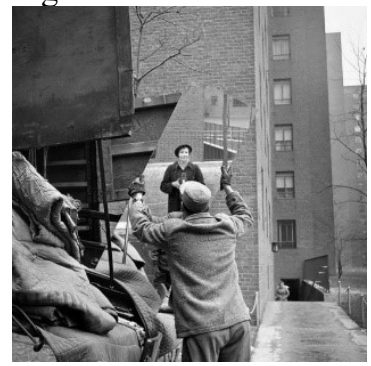

Fonte: Site oficial sobre Vivian Maier $^{2}$.

Outra prática comum em seus autorretratos é o registro do seu reflexo diante de vitrines de lojas e outros tipos de estabelecimentos comerciais, como ocorre nas imagens das figuras 2 e 3.

Fig. 2 - Autorretrato de Vivian Maier

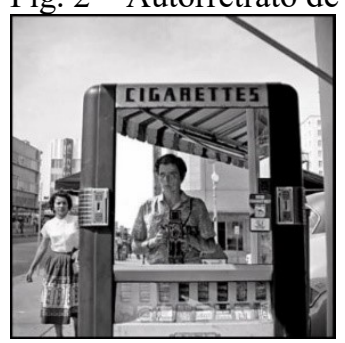

Fonte: Site oficial sobre Vivian Maier³.

${ }^{2}$ Disponível em: < https://goo.gl/Rn9Gye>. Acesso em: 1\%/9/2017.

${ }^{3}$ Disponível em: < https://goo.gl/Rn9Gye $>$. Acesso em: 1\%/9/2017.

INTERIN, v. 23, n. 2, jul./dez. 2018. ISSN: 1980-5276.

Fabíola Paes de Almeida Tarapanoff; Márcia Rodrigues da Costa. O noir e a mise-en-scène em Vivian Maier: o imaginário em torno da babá-fotógrafa. p. 4-21. 
Fig. 3 - Autorretrato de Vivian Maier

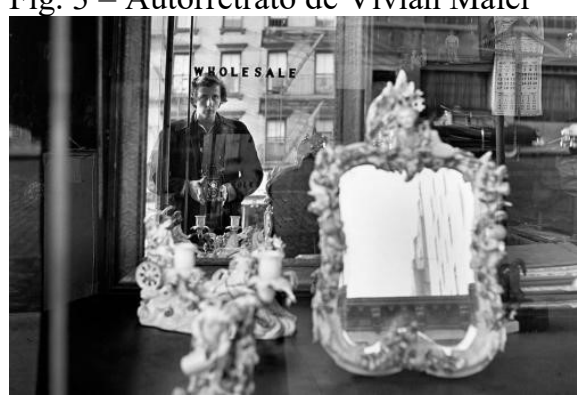

Fonte: Site oficial sobre Vivian Maier ${ }^{4}$.

Esse clima de indagação, de mistério, que pode ser ocasionado pela sua miseen-scène e por sua estética noir, nos leva a pensar a influência do imaginário na leitura do real. Segundo Michel Maffesoli, “o real é acionado pela eficácia do imaginário, das construções do espírito" 5 . Ele é, para além de "[...] um conjunto de elementos e de fenômenos passíveis de descrição"6, [...] configurando-se como "[...] o estado de espírito de um grupo, de um país, de um Estado nação, de uma comunidade etc. O imaginário estabelece vínculo. É cimento social"7:

\footnotetext{
Não se trata de algo simplesmente racional, sociológico ou psicológico, pois carrega também algo de imponderável, um certo mistério da criação ou da transfiguração. O imaginário é uma força social de ordem espiritual, uma construção mental, que se mantém ambígua, perceptível, mas não quantificável. (MAFFESOLI, 2001, p. 75).
}

É o imaginário que produz a imagem, explica Maffesoli e não o contrário: "A existência de um imaginário determina a existência de conjuntos de imagens. A imagem não é o suporte, mas o resultado"8. Referindo-se a todo tipo de imagem, explica que a arquitetura, a arte, o cinema, faz Paris ser o que é. "Isso é uma construção histórica, mas também o resultado de uma atmosfera e, por isso mesmo, uma aura que continua a produzir novas imagens"9.

Que relações então poderiam ser estabelecidas entre o imaginário e a o noir? A seguir, discutimos sobre essa estética no âmbito do cinema.

\footnotetext{
${ }^{4}$ Disponível em: <https:/goo.gl/Rn9Gye>. Acesso em: 1\%/9/2017.

${ }^{5}$ MAFFESOLI, 2001, p. 75.

${ }^{6}$ Ibid., 2001, p. 75.

${ }^{7}$ Ibid., 2001, p. 76.

${ }^{8}$ MAFFESOLI, 2001, p. 76.

${ }^{9}$ Ibid., 2001, p. 76.
}

INTERIN, v. 23, n. 2, jul./dez. 2018. ISSN: 1980-5276. 


\section{Entre luzes e sombras: a estética noir}

Fernando Mascarello (2006, p. 78) afirma que o noir acolhe vários gêneros: “policiais, thrillers, filmes de espionagem, melodramas e até mesmo Westerns". Para o autor, portanto, “[...] o noir não é gênero, nem tom, nem estilo. É um fenômeno, e acima de tudo social (espectatorial)", produzindo fascinação e despertando o desejo por meio da chamada "mística noir” (2006, p. 185).

O noir é "um objeto de beleza" por sua estranheza e fascínio em termos de fantasia (MASCARELLO, 2006, p. 121). Recorrendo a Timothy Corrigan, que afirma que o filme cult e o noir têm um apelo excêntrico e marginal que atraem o espectador, por conta da transformação do público em privado, com vistas à construção de espaços privativos, facilitadores da encenação (experimentação) de novas subjetividades. Com base nessa influência, há no noir um redimensionamento da identidade do homem. “Mas, sendo privado, reluta ainda em se mostrar público..." (MASCARELLO, 2006, p. 186). Assim, a estética noir é definida principalmente por produzir narrativas enigmáticas:

\footnotetext{
[...] os filmes alemães também se destacavam por um tipo de decupagem em que o uso do espaço off screen (o espaço fora da tela) adquiria diferentes significados, especialmente o de fonte de imprevisibilidade e enigma. No emblemático A rua (1923), de Karl Grune, um cidadão burguês (Anton Edhoefer) se perde no caos urbano e nos perigos da noite, em situações que seriam repetidas muitas vezes pelo cinema alemão e pelo cinema noir. Nesse filme, a atenção do espectador é dirigida frequentemente para o espaço fora da tela, enfatizando a ameaça do que não pode ser visto. (MASCARELLO, 2006, p. 91).
}

Segundo Philip Kemp (2011), as origens do noir remontam às sombras, aos ângulos e ao mundo paranoico do Expressionismo Alemão, de cineastas como Friedrich Wilhelm Murnau, com Nosferatu (1922) e Fritz Lang com Metrópolis (1927). Entre os recursos cinematográficos do noir, claramente inspiradas no Expressionismo, estão a iluminação chiaroscuro, ângulos inusitados, flashbacks, narração sobreposta em primeira pessoa, narrativa não linear e diálogos ácidos e rápidos.

O filme O falcão maltês (1941), dirigido por John Huston, com Humphrey Bogart, traz todas as marcas que consagram o estilo: iluminação chiaroscuro e herói

INTERIN, v. 23, n. 2, jul./dez. 2018. ISSN: 1980-5276.

Fabíola Paes de Almeida Tarapanoff; Márcia Rodrigues da Costa. O noir e a mise-en-scène em Vivian Maier: o imaginário em torno da babá-fotógrafa. p. 4-21. 
que tem uma personalidade que oscila entre luzes e sombras. A obra é marcada por características do gênero, como "falta de confiança entre os personagens, pela perda da inocência, por um cenário urbano hostil [...] e por uma sensação de desespero geralmente contrabalançada por um humor mordaz que mantém a plateia à beira da depressão". Em contraposição aos musicais e comédias românticas hollywoodianas do cinema tradicional, com "heróis imaculados e de suas heroínas adocicadas, o cinema noir exibia um pelotão de anti-heróis e femme fatales" (KEMP, 2011, p. 169).

Outro cineasta marcado pela estética expressionista e que compreendeu o potencial do cinema em criar efeitos psicológicos complexos, ao mesmo tempo em que abordava temas controvertidos, foi o mestre do suspense Alfred Hitchcock, conforme Rohmer e Chabrol (1979 apud BUCKLAND, 2010). Em A sombra de uma dúvida (1943), a jovem Charlie desvenda o passado criminoso de seu tio Charlie, trazendo como marcas do noir o falso moralismo e o uso de low-key (luzes e sombras).

O noir também esteve presente em suas obras por meio do tema da culpa, do desejo, do homem acusado injustamente, da mulher fatal, com ênfase na edição e na montagem e recursos narrativos como flashbacks, câmera subjetiva, com o ponto de vista do personagem, como em Janela indiscreta (1953) e Um corpo que cai (1958) e espaços confinados, claustrofóbicos, que influem na psicologia dos personagens, como Festim diabólico (1948).

Esse confinamento de espaço leva a uma dramatização típica do teatro. Teatral, Hitchcock (IMDB, 2016) deixava sua marca, aparecendo nos filmes logo no início, sempre discreto, buscando não desviar a atenção da história. A mise-en-scène é um aspecto central tanto na obra do cineasta quanto de Vivian Maier, e lembra as aproximações entre a fotografia e o teatro por conta da construção da cena. Falemos, a seguir, um pouco sobre a mise-en-scène e sobre sua presença na fotografia de Maier.

\section{Mise-en-scène}

Fernão Pessoa Ramos define mise-en-scène como o espaçamento de corpos e objetos em cena, uma herança do teatro, do final do século XIX e início do século XX, que e surge com a valorização do diretor, responsável pela criação da narrativa no

INTERIN, v. 23, n. 2, jul./dez. 2018. ISSN: 1980-5276.

Fabíola Paes de Almeida Tarapanoff; Márcia Rodrigues da Costa. O noir e a mise-en-scène em Vivian Maier: o imaginário em torno da babá-fotógrafa. p. 4-21. 
espaço cênico. Na mise-en-scène singular do cinema dos anos 1950 grandes diretores e atores criaram uma linguagem própria cinematográfica.

\begin{abstract}
Mise-en-scène no cinema significa enquadramento, gesto, entonação da voz, luz, movimento no espaço. Define-se na figura do sujeito que se oferece à câmera na situação de tomada, interagindo com outrem que, por trás da câmera, lhe lança o olhar e dirige sua ação. (RAMOS, 2012, p. 54).
\end{abstract}

Jacques Aumont (1992/93, p. 229), lembrando que o cinema é criado a partir do teatro e da pintura, afirma que quando se traz o teatro no cinema torna-se "sensível uma estrutura de espaço, fundada sobre o fechamento e a abertura". Ressalta essa influência no trabalho dos cineastas Jean Renoir, mais realista, e Jacques Rivette, com clara influência teatral, e lembra que nos anos 1940 e 1950 o cinema de Hollywood foi fortemente influenciado por cineastas europeus, como Otto Preminger, cujos filmes “são remarcáveis pela precisão maníaca dos gestos, pela movimentação dos corpos, pelo ritmo" (AUMONT, 1992/93, p. 229).

O cinema apresenta nos anos 1930 a 1950 uma estética que "é uma concepção de mise-en-scène como cálculo, como mise-en-place, como construção de ritmo pela montagem, como marcação de elementos significantes pelo enquadramento", explica Aumont (1992/1993, p. 229). Nessa clara influência da pintura e da fotografia, Aumont considerava Louis Lumière o último impressionista, com sua preocupação pictórica em relação ao impalpável, onde a luz não pode ser tocada; ao irrepresentável, que é um desafio à habilidade do pintor, e o fugidio, que é fixar o efêmero, e ao chamado instante impregnante, tema caro também à fotografia, conforme o autor (2004, p. 35). “[...] os efeitos de realidade são paradoxais e, em sua vertente, são logo os fantasmas que encontramos: o fantástico, o de Nosferatu e de Vampyr, surgindo como efeito exacerbado da realidade mais banal e tranquila. O extraordinário no ordinário” (AUMONT, 2004, p. 37).

Iluminação, expressividade e marcação de elementos pelo enquadramento são temas caros à fotografia e ao cinema. Temos como hipótese que a obra de Vivian Maier é pontuada por uma mise-en-scène impregnada pela estética noir, tal qual ocorre no cinema de Hitchcock. A forma como ela constrói, ficciona sua imagem, é tema da nossa próxima discussão.

INTERIN, v. 23, n. 2, jul./dez. 2018. ISSN: 1980-5276. 


\section{Realidade, ficção e imaginário em Vivian Maier}

Observando as fotos de Vivian Maier, busquemos identificar em sua estética o imaginário que cerca a sua obra, com a presença de elementos da estética noir. A imagem da fotógrafa é indício de algo que está por trás da tela (a vida enigmática e oculta) ou indicativo de uma presença que surge na cena. Essa relação com algo que está fora da tela, que Philippe Dubois (1993) denominaria de fora-de-campo, é visível na narrativa que permeia a vida de Maier e que contamina o olhar do espectador. É como se essa narrativa, esse imaginário sobre ela atuasse com seu poder de sugestão nesse espaço que o autor chama de espaço offscreen, um olhar impulsionado pelo que está dentro e fora da imagem, pela emoção, pelo real e pelo hiperreal.

Esse imaginário se materializa e é reforçado pela estética da imagem. Do ponto de vista formal, marca forte do noir é o uso da fotografia em preto e branco, além dos contrastes acentuados entre claro e escuro. É dessa forma que Maier comunica, por meio da sombra e da luz, que divide a sua imagem, a relação dual e ambígua de sua vida, marcada pelo que revela e o que oculta, pela dupla função que executava como fotógrafa e babá, pelo mistério que guardava.

A imagem ressalta o rosto e o olhar de Vivian Maier, destacando, por meio da iluminação, uma expressão séria e quase sombria, dividida entre luz e sombra, favorecendo uma narrativa de ocultamento de um segredo. Não à toa o noir é um termo que, logo que cunhado, foi empregado para denominar "obras de tons escurecidos, temática e fotograficamente", de "representação crítica e fatalista da sociedade americana" e que buscavam a "subversão à unidade e estabilidade típicas do classicismo de Hollywood" (MASCARELLO, 2006, p. 179).

A iluminação low-key (MASCARELLO, 2006, p. 181), com utilização de sombras, influência do noir, aliada à expressividade do rosto e do gesto da fotógrafa, provoca um olhar questionador de quem observa. Uma característica predominante do noir é o clima enigmático, típico dos filmes policiais e de suspense:

INTERIN, v. 23, n. 2, jul./dez. 2018. ISSN: 1980-5276. 
Fig. 4 - Autorretrato de Vivian Maier

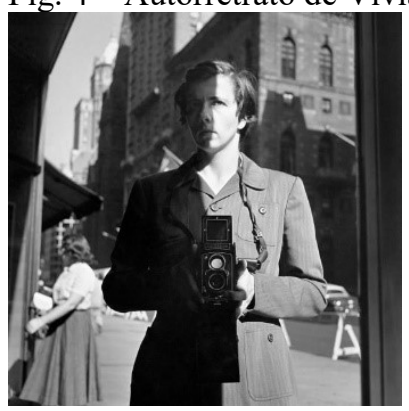

Fonte: Site oficial sobre Vivian Maier ${ }^{10}$.

Nesta e nas demais imagens aqui selecionadas a imagem de Vivian Maier continua surgindo no reflexo do espelho (ou vidro), outra característica do noir, rico na utilização de elementos como “[...] espelhos, janelas (o quadro dentro do quadro)", conforme Mascarello (2006, p. 179). O espelho surge como revelação, trazendo à luz a obscuridade, convidando o espectador a penetrar em um universo desconhecido.

Fig. 5 - Autorretrato de Vivian Maier

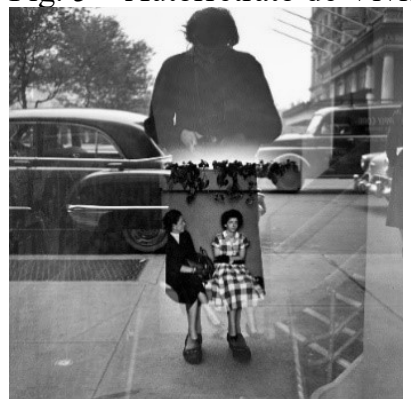

Fonte: Site oficial sobre Vivian Maier ${ }^{11}$.

Fig. 6 - Autorretrato de Vivian Maier

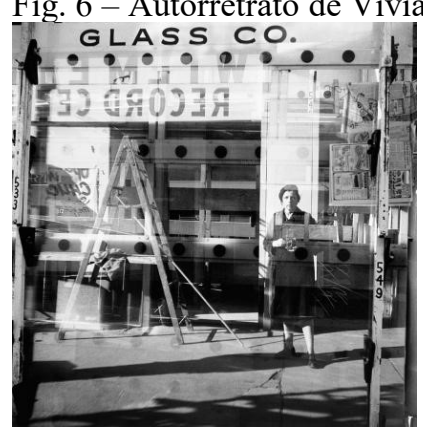

Fonte: Site oficial de Vivian Maier ${ }^{12}$.

${ }^{10}$ Disponível em: < https://goo.gl/Rn9Gye>. Acesso em: 1\%/9/2017.

${ }^{11}$ Disponível em: < https://goo.gl/Rn9Gye>. Acesso em: 1\%/9/2017.

12 Disponível em: <https://goo.gl/Rn9Gye> Acesso em: 1\%/9/2017.

INTERIN, v. 23, n. 2, jul./dez. 2018. ISSN: 1980-5276.

Fabíola Paes de Almeida Tarapanoff; Márcia Rodrigues da Costa. O noir e a mise-en-scène em Vivian Maier: o imaginário em torno da babá-fotógrafa. p. 4-21. 
Fig. 7 - Autorretrato de Vivian Maier

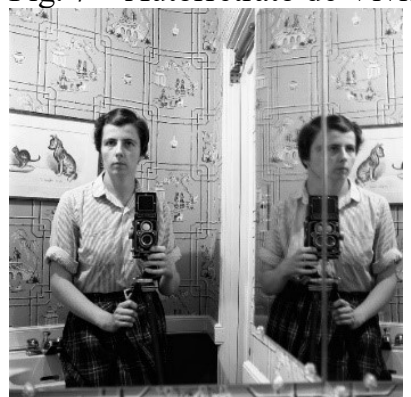

Fonte: Site oficial de Vivian Maier ${ }^{13}$.

Fig. 8- Autorretrato de Vivian Maier

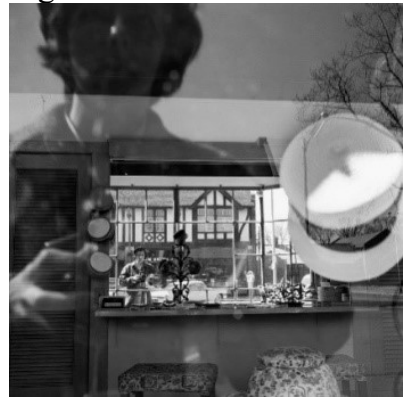

Fonte: Site oficial sobre Vivian Maier ${ }^{14}$.

Nas figuras 5 e 8 sua imagem surge como uma sombra onipresente que encobre todo o cenário e de onde emergem, do reflexo do espelho ou vidro, outras imagens (de duas mulheres, na 5, e a sua própria, na 8). Ou seja, o oculto, o escuro, prevalece sobre o claro, o revelado. Na imagem 6 e 7 ela revela ao espectador a sua presença, seu rosto, sua identidade, mas guarda na expressão silenciosa o mistério que permanece oculto por trás de sua figura. $\mathrm{O}$ espelho parece confundir o olhar do espectador, protegendoa.

Nas quatro imagens ela anuncia sua presença pelo reflexo (do espelho, vidro ou sombra) - ou seja, ela é espectro, no sentido de aparição, visão, de retorno da imagem do morto. Sua mise-en-scène traz sempre a expressão facial contida, que surge do silêncio, da sombra, do jogo entre o claro e o escuro.

A imagem de seu rosto e de seu corpo de expressões congeladas remete a de um morto. Com relação ao tempo, a foto promove uma imobilização eterna da imagem de Maier, fixa seu rosto, promove uma passagem, transposição do "tempo evolutivo ao tempo petrificado, do instante à perpetuação, do movimento à mobilidade, do

${ }^{13}$ Disponível em: <https://goo.gl/Rn9Gye>. Acesso em: 1\%/9/2017.

${ }^{14}$ Disponível em: <https://goo.gl/Rn9Gye>. Acesso em: 1\%/9/2017.

INTERIN, v. 23, n. 2, jul./dez. 2018. ISSN: 1980-5276. 
mundo dos vivos ao reino dos mortos, da luz às trevas, da carne à pedra", explica Dubois ${ }^{15}$. Essa passagem, tal qual a morte, provoca uma áurea de medo, presente na imagem da Medusa, no seu olhar que alude ao olhar do morto "petrificado, congelado, estratificado por ter sido visto - por ser visto a si mesmo como outro. A petrificação fotográfica não é nada além dessa passagem, infernal e especular" ${ }^{16}$. Assim, a fotografia de Maier surge como processo de fantasmização do seu próprio corpo ${ }^{17}$. Nessa passagem, "transposição", ao invés de perda, tem-se "uma outra forma de sobrevida pelo corte e fixação das aparências" 18 , agora uma "película da eternidade"19. Uma máscara pelo olhar cortante ou cortado, onde a câmera "executa o corte e congela" ${ }^{20}$ a cena, e sua imagem é perpetuada pela câmera, pelo reflexo.

Aqui, ao se falar da figura mascarada (a máscara de Medusa), tem-se a imbricação entre imaginário e simbólico. "Para além da argumentação persuasiva, impõe-se a sedução, ou seja, a emoção", salienta Maffesoli (2001, p. 77). O imaginário do cinema e da fotografia trabalha os símbolos, os heróis e mitos, os ritos que são atualizados". Gilbert Durand (2000, p. 10), que investiga a imaginação simbólica, mostra que não há diferença entre simbólico e imaginário, ambos se contaminam, afirma o autor.

No autorretrato por sombra, reflexo, espelho ou disparador automático, a imagem de Vivian Maier emerge apresentando também o que Philippe Dubois chama de um "problema de duplo" (1993, p. 343-344). Em seu autorretrato de frente para uma vitrine nos deparamos com a seguinte provocação fantasmagórica: "Ei-lo, esse Sujeito em sua corrida louca entre dois mundos" (1993, p. 351), afirma o autor, ao falar de aparências que se conflitam ou dialogam na construção de uma realidade e de uma ficção que se misturam. Ao nos fitar, o olhar da fotógrafa anuncia sua presença que retorna do passado.

Trazida de volta pela fotografia, a imagem de Maier expõe o seu "eu múltiplo, em tensão", conforme José Antônio Leitão (2008, p. 213), um interior invisível,

\footnotetext{
${ }^{15}$ DUBOIS, 1993, p. 168.

${ }^{16}$ DUBOIS, 1993, p. 169.

17 Ibid., p. 222.

${ }^{18}$ Ibid., p. 169.

${ }^{19}$ Ibid., p. 170.

${ }^{20}$ Ibid., p. 172.
}

INTERIN, v. 23, n. 2, jul./dez. 2018. ISSN: 1980-5276. 
múltiplo, complexo, fugidio - que se esquiva no rosto por meio do retrato, que revela o "transitório, o complexo, o peculiar, o invisível" e que, por isso, podem conduzir o retrato para lá da imagem mimética. Eis o potencial da imagem “que contém o olho no centro e segura um compasso aberto. Atração da imagem para fora das aparências para melhor retratar. Interior invisível, complexo, múltiplo" (LEITÃO, 2008, p. 213).

O olhar, enquanto uma categoria de signo "embreante fora de campo" (MASCARELLO, 2016, p. 187), é categoria de índice que ajuda a formar uma atmosfera de mistério, compondo o clima noir que circunda Vivian Maier. Em vários de seus autorretratos verifica-se o olhar de Maier quase sempre frontal, como se ela fitasse o espectador na tentativa de com ele se comunicar, tal qual um fantasma que anuncia sua presença, uma aparição. Neles ela aparenta a mesma aparência séria por meio de uma expressão distante, tímida e fria, como ocorre nos filmes de suspense ou terror. "Quando o rosto era representado em plena visão frontal, como na máscara trágica conhecida como gornonêion, a sua intenção era deliberadamente assustar, lembrando ao espectador a Górgona mítica, cuja visão petrificava aqueles que a fitavam", recorda Alberto Manguel (2001, p. 181), recorrendo à cultura grega dos tempos de Homero.

As roupas discretas, masculinas, frias e imperceptíveis tais quais as de um fantasma ajudam a compor o figurino dessa personagem de hábitos ditos extravagantes, construindo, ficcionando e revelando as identidades de babá e da fotógrafa. Vivian Maier traz seu testemunho por meio do invisível da fotografia, da imortalidade da alma.

\footnotetext{
Os mortos povoam as fotografias com os seus corpos: os seus corpos ainda vivos, convocados em fotografia (tornada natureza-morta) para o interior de outras fotografias de vivos (hoje mortos) - e os seus corpos já mortos, encenando a vida ou aceitando a morte. Mas os mortos povoam as fotografias até sem os seus corpos: plasmas, hesitando entre o visível e o invisível que se podia acreditar acessível à fotografia. (LEITÃO, 2008, p. 212).
}

Os autorretratos da fotógrafa nos fitam e provocam em nós certo voyeurismo, pelo desejo e pela mística que sua figura desperta, intrigando o espectador diante das possibilidades que sua figura ou suas representações suscitam no imaginário de quem olha. No artigo "O fotográfico como retrato e ready made: a propósito de Alfred Hitchcock" (2008), José António Leitão fala do retrato enquanto apropriação, ficção,

INTERIN, v. 23, n. 2, jul./dez. 2018. ISSN: 1980-5276.

Fabíola Paes de Almeida Tarapanoff; Márcia Rodrigues da Costa. O noir e a mise-en-scène em Vivian Maier: o imaginário em torno da babá-fotógrafa. p. 4-21. 
o que, em nosso entendimento, leva o espectador a fixar sua atenção na história, imaginando o que há por trás da imagem (o imaginário, o espaço off screen), atraindose pelo enigma do que é real e o que não é, do que está oculto e o que está visível, fantasiando ou imaginando uma ou outras histórias para além do que a própria imagem apresenta:

Toda a tradição retratística se estende, em tensão, entre verdades e mentiras, em frequentes trocas de papéis: visível-invisível, superfícieprofundidade, interior-exterior, material-imaterial, duradouro-passageiro, ficção-realidade. Em troca de papéis porque a autenticidade do retrato se desloca entre os termos - e não só de um para o outro, mas, literalmente, no meio deles, em territórios contaminados por ambos, por vários, por todos. (LEITÃO, 2008, p. 210).

$\mathrm{Na}$ fotografia de Vivian Maier estão evidentes tanto um elemento racional (a comprovação de sua imagem, que demonstra que ela existiu como fotógrafa) quanto "o onírico e o lúdico, a fantasia, o imaginativo, o afetivo, o não-racional, o irracional, os sonhos, enfim, as construções mentais potencializadoras das chamadas práticas", como destacou Maffesoli (2001, p. 77). O criador da imagem capta "o que circula na sociedade", de forma que sua criação corresponde a "uma atmosfera" (2001, p. 80), dá forma ao informal ou disforme. Tanto o cinema quanto a fotografia trabalham "com arquétipos, em sintonia com o que está enraizado, vivido no social” (p. 80). A imagem, o cinema, entram "em sintonia com o espírito coletivo" e conforme Maffesoli, "são tecnologias do imaginário que bebem em fontes imaginárias para alimentar imaginários" (p. 80).

Fig. 9 - Frame do filme Finding Vivian Maier

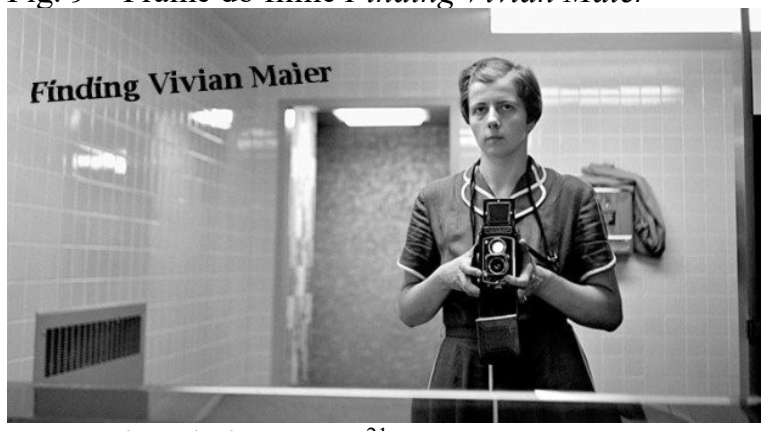

Fonte: Site Obvious Mag. ${ }^{21}$

${ }^{21}$ Disponível em: <https://goo.gl/3KUUWg>. Acesso em: 3 jul. 2018.

INTERIN, v. 23, n. 2, jul./dez. 2018. ISSN: 1980-5276. 
Fig. 10 - Alfred Hitchcock em Psychose

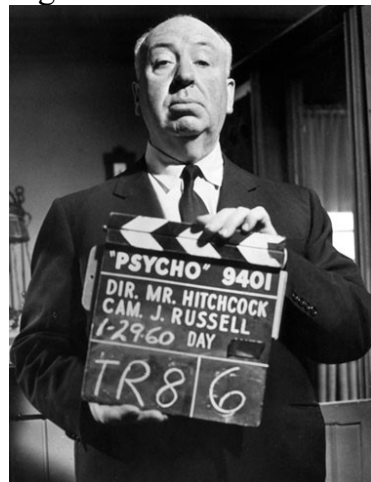

Fonte: Site Today I Found Out. ${ }^{22}$

Fig. 11 - Alfred Hitchcock em Janela Indiscreta

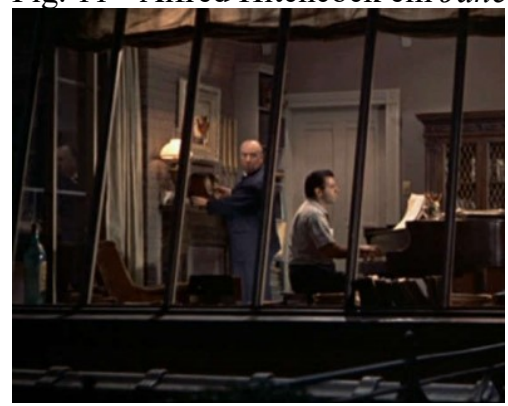

Fonte: Site Pausa Dramática. ${ }^{23}$

\section{Considerações Finais}

A mise-en-scène de Maier (enquadramento, gesto, iluminação e movimento no espaço) traz as características típicas do noir, seja pela via do enigma, seja pela veia da curiosidade, do inusitado, da influência teatral, da expressividade, da presença na ausência, dos efeitos psicológicos complexos. Sua fotografia é presença evidente de uma criação de pose e de composição da personagem, o que ajuda a criar um imaginário em torno de sua figura. Como nas estéticas cult e noir, um forte apelo nas suas imagens é também o seu lado excêntrico e marginal, encenando e experimentando por meio do autorretrato novas subjetividades ou identidades. A sombra (que caracteriza o autorretrato porque se trata de criar um duplo), o ângulo frontal que encara e por vezes amedronta, a figura séria e enigmática, com elementos da monstruosidade, do diferente, tal qual Nosferatu e Medusa, com sua máscara mortífera, são os outros elementos fortes do noir. Sua alusão ao aspecto ilusório da

${ }^{22}$ Disponível em: <https://goo.gl/vX7Kad $>$. Acesso em: 3 jul. 2018.
${ }^{23}$ Disponível em: $<$ https://goo.gl/i7gj1 J > Acesso em: 3 jul. 2018.

INTERIN, v. 23, n. 2, jul./dez. 2018. ISSN: 1980-5276.

Fabíola Paes de Almeida Tarapanoff; Márcia Rodrigues da Costa. O noir e a mise-en-scène em Vivian Maier: o imaginário em torno da babá-fotógrafa. p. 4-21. 
fotografia - a mise-en-scène com os espelhos, bastante presente nos seus autorretratos - revela uma influência do Expressionismo, trazendo à cena o complexo e o sombrio.

Este resultado ela alcança por meio de recursos fotográficos igualmente presentes no noir: a iluminação chiaroscuro, o exercício da fotografia em preto e branco, o uso de ângulos inusitados, de espelhos e vitrines, e uma narração que utiliza a si mesma como personagem, transformando o eu em objeto. Hitchcock também brincava com sua imagem e, assim como nos sentimos voyeurs, cúmplices do cineasta, de seus crimes e suas histórias, também somos chamados a desvendar Vivian Maier por meio de seus autorretratos. Neste sentido, sua fotografia se apresenta eminentemente como imaginário (fantasia).

A força das imagens de Vivian Maier está nessa antítese: a fixação pela autoimagem (self) em um jogo de espelhos não pressupõe um foco narcisista ou egocêntrico no eu, típica nestes tempos de explosão de imagens e de banalização do self. Extremamente discreta, foi babá por quarenta anos e ocultou detalhes de sua vida ou de sua enorme paixão pela fotografia, imagens publicadas somente após sua morte, em 2009. Trouxe para si a relutância diante do aspecto público da imagem, característica do noir.

Ao manter secreta, privada, a sua fotografia, inconscientemente Maier dirigiu o olhar do espectador para o espaço fora da tela (espaço off screen), ampliando o desejo dele de ver o que não pode ser visto, o que está atrás da cortina, da tela, para o mistério de sua vida-obra e todo o imaginário em torno dela. Com a câmera sempre à mão, Vivian Maier revela ao espectador a artista, identidade que coexistia secretamente com a da babá, função que lhe proporcionava uma grande interlocução com a cidade, uma espécie de estúdio aberto para os seus experimentos.

Se Maffesoli explica que o imaginário individual pode refletir, no artístico, o imaginário de um grupo, logo, o imaginário de Vivian Maier, “determinado pela ideia de fazer parte de algo", consiste "em partilhar uma linguagem, uma atmosfera, uma ideia de mundo, uma visão das coisas, na encruzilhada do racional e do não-racional" (2001, p. 80), o seu universo permeado pelo seu universo noir.

A fotografia de Maier é exemplo de que o campo de representação também inclui o imaginário, formado por imagens e discursos, extrapolando o caráter realista da fotografia de Maier e dotando-a da característica de "imaginário no real” (DUBOIS,

INTERIN, v. 23, n. 2, jul./dez. 2018. ISSN: 1980-5276.

Fabíola Paes de Almeida Tarapanoff; Márcia Rodrigues da Costa. O noir e a mise-en-scène em Vivian Maier: o imaginário em torno da babá-fotógrafa. p. 4-21. 
1993, p. 348), atuando, conforme Philippe Dubois, não apenas como índice, mas também como imaginação, fantasma, ficção. A obra de Vivian Maier está impregnada da essência desta artista, enquanto produtora de imaginários sobre a sua vida-obra (o fora da tela), gerando toda mística e desejo pelas histórias que ela mostra e que oculta, um verdadeiro reservatório do imaginário, termo cunhado por Juremir Machado Silva (apud GISLENE SILVA, 2010, p. 6), por "agregar sentimentos, lembranças leituras de vida". Enquanto "motor, elemento propulsor", o imaginário, conforme Silva, "retorna ao real, seria um sonho que realiza a realidade, funcionando como catalisador, estimulador e estruturador das práticas". Assim, "todo indivíduo submete-se a um imaginário preexistente e todo sujeito é um inseminador de imaginários" (2010, p. 6).

Como Hitchcock, Vivian coloca-se em cena e surpreende. No que aparenta ser, à primeira vista, algo ordinário (a simples figura de uma babá), eis que surge em seu próprio autorretrato a figura extraordinária de uma fotógrafa que por anos ocultou seu talento, um "efeito exacerbado da realidade mais banal e tranquila. O extraordinário no ordinário", como escreveu Aumont (2004, p. 37).

Tal qual o cineasta, Vivian Maier tinha a capacidade de, no poético do banal cotidiano, buscar fixar o mistério da vida por meio de seus personagens e enquadramentos. E, em um talvez inconsciente desejo de despertar a imaginação, ambos acabaram deixando impressos em suas imagens o mistério de suas próprias vidas. Em suas imagens ela imprimiu a marca autoral de uma artista, alimentando um vasto imaginário sobre si mesma e sobre sua fotografia.

\section{REFERÊNCIAS}

AUMONT, Jacques. O olho interminável [cinema e pintura]. Tradução de Eloísa Araújo Ribeiro. São Paulo: Cosac Naify, 2004.

AUMONT, Jacques. 'Renoir le Patron, Rivette le Passeur'. In: Le Théâtre dans le Cinema - Conferences Du Collége d'Histoire de l'Art Cinématographique no3. Paris. Cinemathèque Française/Musée du Cinema. 1992/93.

BUCKLAND, Warren. Understand film studies. Londres: Hodder Education/Hachette UK Company, 2010. 
DUBOIS, Philippe. O ato fotográfico e outros ensaios. Tradução de Marina Appenzeller. Série Ofício de Arte e Forma. $7^{a}$ edição. Campinas: Papirus, 1993.

DURAND, Gilbert. A imaginação simbólica. Lisboa. Portugal: Edições 70, 2000.

DYER, Geoff. “Geoff Dyer sobre Vivian Maier.” In: MALOOF, John (Org). Vivian Maier: uma fotógrafa de rua. São Paulo: Autêntica, 2014.

FINDING Vivian Maier. Direção: Charlie Siskel e John Maloof. EUA: 2013.1 DVD (84 minutos).

IMDB - Alfred Hitchcock. Disponível em: $<$ https:/goo.gl/3v1yhY $>$. Acesso em: 15 jul. 2016.

KEMP, Philip. Tudo sobre cinema. Tradução de Fabiano Morais. Rio de Janeiro: Sextante, 2011.

LEITÃO, José Antônio. O fotográfico como retrato e "ready made": a propósito de Alfred Hitchcock. Revista do IHA, no 5, p. 208-217. Lisboa: Faculdade de Ciências Sociais e Humanas - Instituto de História da Arte, 2008. Disponível em: $<$ https://goo.gl/fff3ef $>$. Acesso em: 10 jul. 2016.

MAFFESOLI, Michel. O imaginário é uma realidade. Entrevista concedida a Juremir Machado da Silva. Revista FAMECOS, no 15, p. 74-81. Porto Alegre: Summus, ago. 2001. Disponível em: <https://goo.gl/gNterg>. Acesso em: 21 mai. 2016.

MALOOF, John (Org). Vivian Maier: uma fotógrafa de rua. São Paulo: Autêntica, 2014.

MASCARELLO, Fernando. Film noir. In: História do cinema mundial. Fernando Mascarello (Org). (Coleção Campo Imagético). Campinas, SP: Papirus, 2006.

RAMOS, Fernão Pessoa. A mise-en-scène realista: Renoir, Rivette e Michel Mourlet. In: XIII Estudos de Cinema e Audiovisual SOCINE. 13., 2012, São Paulo. Anais eletrônicos... São Paulo: Socine, 2012, v. 1, p. 53-68. Disponível em: < https://goo.gl/aTCThf >. Acesso em: 29 jun. 2018.

SILVA, Gislene. Imaginário coletivo: estudos do sensível na teoria do jornalismo. In: XIX Encontro da Associação Nacional dos Programas de Pós-Graduação em Comunicação, 19., 2010, Rio de Janeiro. Anais eletrônicos... Rio de Janeiro: Compós, jun. 2010. Disponível em: <https://goo.gl/GFbJZs $>$. Acesso em: $1^{\mathrm{o}}$ jun. 2016.

Recebido em: 05.10.2017

Aceito em: 09.12.2017

INTERIN, v. 23, n. 2, jul./dez. 2018. ISSN: 1980-5276. 